\title{
Running Laboratory Experiments via the World Wide Web
}

\author{
Jim Henry \\ The University of Tennessee at Chattanooga
}

\begin{abstract}
The chemical engineering laboratories at the University of Tennessee at Chattanooga have been made available for students to use via the World Wide Web. Students can conduct lab experiments from remote sites. This paper describes the hardware and software that is used for this facility and discusses strengths and "opportunities for improvement" that have been observed in this development.
\end{abstract}

The web address for the lab is http://chem.engr.utc.edu.

\section{Hardware and Software}

The chemical engineering laboratories have been using desktop computers for data acquisition and control of engineering equipment since 1990. The students conduct experiments to observe steady-state and transient operating performance, accomplish system identification and, in some cases, design feedback controllers for the systems. The data acquisition and control software is written with LabVIEW software (from National Instruments, http://www.natinst.com ). Controller design, if done, involves tuning two feedback controllers: a proportional controller and a proportional-integral controller.

The computers are all networked with ethernet and have internet (IP) addresses. A web-server program was developed which allows students to conduct experiments using widely available web browsers. The students conduct the experiments either from computer labs on campus or from remote computers via the world wide web.

\section{Hardware Stations}

The controls labs and some unit operations experiments are web-accessible. Seven different stations for controls systems experiments and an additional seven stations for unit operations experiments are available. They are listed in Table 1. 


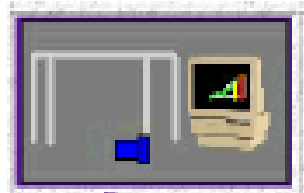

Pressuks

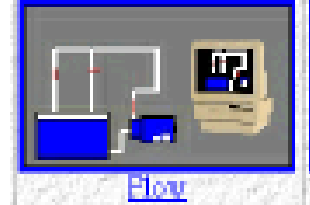

Bloy

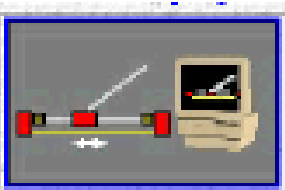

Positice

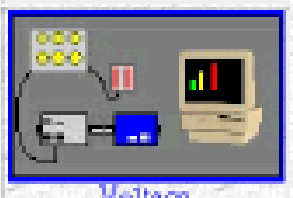

Voltace

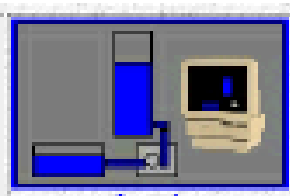

Lanel

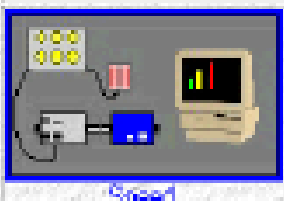

Sreed
Each of the "controls" stations is a single-input, single output system. All are inherently stable systems when run in open-loop configuration. That is, if you specify a fixed input value, the system will reach a constant steady-state condition. The desired web station is chosen by a graphic web page shown in Figure 1.

Figure 1. Selection page for Experimental Stations

Figure 2 shows a picture of the level control station. Pictures of all the equipment are available on the Web site. More complete descriptions of some of these have been given before (Henry [1] and Henry [2]).

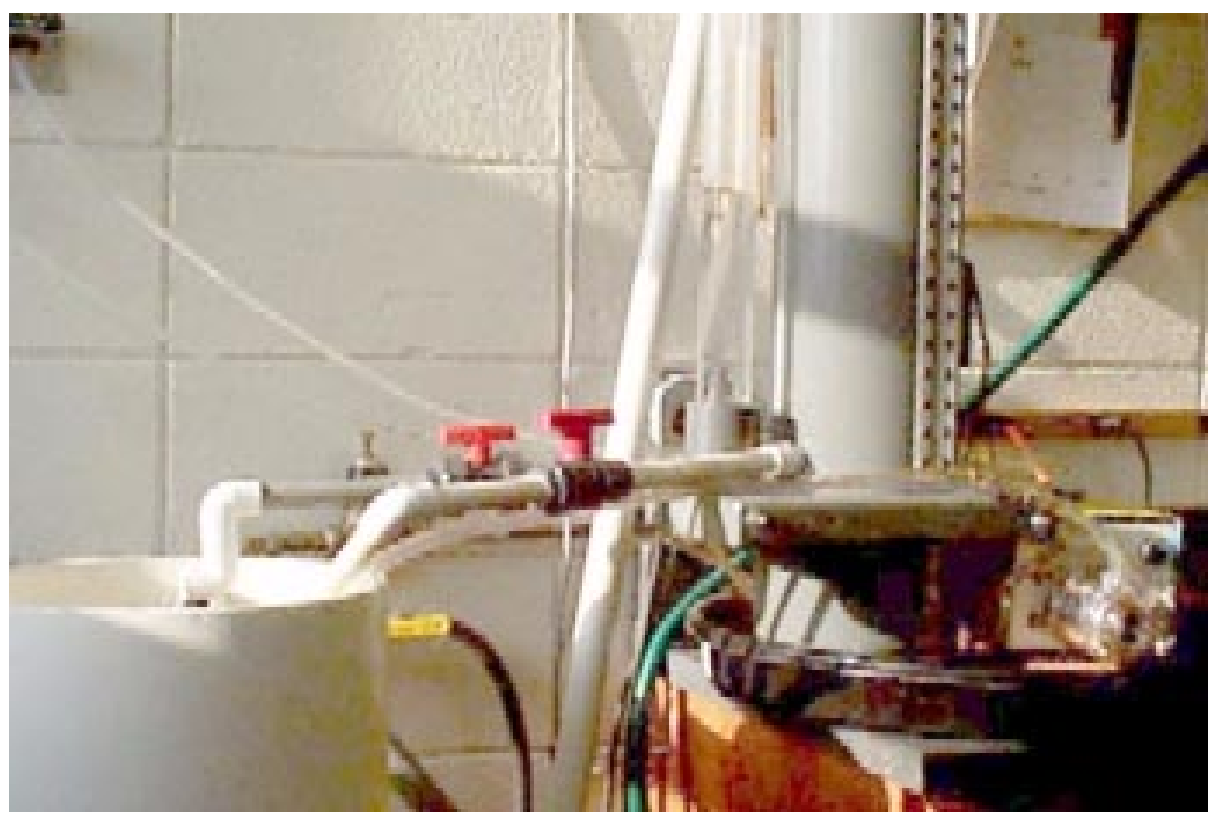

Figure 2. Photo of Level control station

Table 1. Experimental Stations available

\begin{tabular}{|c|l|l|}
\hline \multicolumn{2}{|c|}{ Controls Laboratory } & Response \\
\hline Statio & Description & \\
\hline 2 & $\begin{array}{l}\text { Pressure control by varying the speed of a blower } \\
\text { Speed control of a motor-generator set by varying the signal to the } \\
\text { motor power supply }\end{array}$ & \\
3 & $\begin{array}{c}\text { Voltage control of a motor-generator set by varying the signal to the } \\
\text { motor power supply }\end{array}$ & Fast \\
4 & $\begin{array}{l}\text { Flow control in a closed flow loop by varying the speed of the pump } \\
5\end{array}$ & Position control in a cart-on-a-rail by varying the torque in the motor \\
6 & Level control in a water tank by varying the speed of the water pump &
\end{tabular}




\begin{tabular}{|c|l|l|}
\hline 7 & $\begin{array}{l}\text { Temperature control in a heat exchanger by varying the flow rate of the } \\
\text { hot water supply }\end{array}$ & Slow \\
\hline \multicolumn{2}{|c|}{ Unit Operations Laboratory } & \\
\hline 8 & Heat Exchange & \\
9 & Dehumidification & Slow \\
10 & Batch Dryer & \\
11 & Gas-fired Heater & \\
12 & Packed-bed Absorption Column & \\
13 & Flow through Porous Media & \\
14 & Heat Exchange -- 2 & \\
\hline
\end{tabular}

Stations \#1 through \#4 and \#7 in Table 1 all have variable-voltage, variable-frequency (VVVF) power supplies to vary the speed of 3-phase motors that provide the motive force in the experiments. Each of these VVVF power supplies receive a 0-10 volt control signal from an analog output channel on an A/D board in the control station. The position control station (\#5) receives its motive power from a DC-motor that is controlled by a pulse-width modulated (PWM) power supply. The PWM receives a 0-10 volt control signal as just described. The level control station (\#6) receives its motive power from a variable speed laboratory pump that is controlled by a 4-20 ma current signal from the control station.

The first 5 stations listed in Table 1 are fast-acting systems. They have response times on the order of 1-second; typically, an experiment can be completed within 10 to 30 seconds.

These systems are called the "fast" systems. The last 2 listed control stations have response times on the order of 1-minute; typically, an experiment can be completed on these systems within 10 to 30 minutes. These systems are called the "slow" systems. The significance of this will be brought out below.

Station \#1, the pressure control station, involves controlling the pressure of air in a manifold that is fed by an air blower powered by the 3-phase motor. The air pressure is sensed by a piezoresistive pressure transducer and a $0-10$ volt signal is sent to the control station. The manifold feeds three outlet ducts; two of those ducts can be closed by control of the computer to provide different loads on the blower. The timing of the closing of the ducts is under the control of the Web user.

Stations \#2 and \#3, the speed and the voltage control stations, involve a self-excited DCgenerator driven by the 3-phase, 5-hp motor. In the "speed" mode, the speed is detected by a chopper wheel and photocell on the drive shaft. The frequency of the pulse train signal out of the photocell is converted into a 0-10 volt signal and then sent to the control station. In the "voltage" mode, the voltage out of the generator ( $0-85$ volts) is converted by a voltage divider into a $0-10$ volt signal and then sent to the control station. The electrical power output of the generator can be connected to either one or both of 2 banks of resistance load. The loads are sets of eight 300 watt, 120 volt light bulbs. 
Station \#4, the flow control station, involves the control of flow of water in a line that is fed by water pump powered by the 3-phase motor. The water flow rate is measured by a Micro-Motion coriolis-force mass flow meter. The output signal is in the form of a 4-20 ma current signal which is sent to the control station. The manifold feeds two other lines; those lines can be closed by control of the computer to provide different loads on the pump. The timing of the closing of the lines is under the control of the Web user.

Station \#5, the position control station, consists of a cart riding on rails that is moved with a DC motor pulling on the cart. The cart's motion is constrained by a spring attached on the other side. The drive motor is powered by a DC signal that is pulse-width modulated by the control signal from the controller. The cart's position is sensed by a voltage across a potentiometer which is attached to the pulley which moves the cart.Station \#6, the level control station, involves controlling the level of water in one of two tanks that are supplied by the variable-speed laboratory pump. The choice of which tank to use is made by a 3-way valve under computer control. The two tanks have different cross-sectional areas, so their time constants are different. The pressure is sensed by a piezo-resistive pressure transducer that measures the hydrostatic pressure at the bottom of the tank. The output signal is in the form of a 0-10 volt signal, which is sent to the control station.

Station \#7, the temperature control station, involves the controlling the temperature of water in a reservoir that contains two heat-transfer coils. One coil has hot water flowing at a variable rate, under computer control. The hot water is heated locally with a domestic water heater; the hot water flows in a closed recycle loop. The other coil has (utility) cooling water flowing at one of three rates, under computer control; the cold water flow is once-through, and then the water is sent to the drain. The different cooling water flow rates provide different loads for the heating system. The temperature in the reservoir is measured with a 100-ohm, platinum RTD that is connected to an RTD-voltage signal conditioner module. The output signal is in the form of a 010 volt signal which is sent to the control station. The temperatures of the inlets and outlets of the hot and cold water are also measured. The flow rates of the hot and cold water are measured by paddle wheel flow-meters; their output signal is in the form of 4-20 ma current signals which are sent to the control station.

A summary of these system descriptions is in Table 2 .

Table 2. Experimental Stations summary

\begin{tabular}{|l|l|l|l|}
\hline System & $\begin{array}{l}\text { Manipulated } \\
\text { variable }\end{array}$ & $\begin{array}{l}\text { Disturbance } \\
\text { variable }\end{array}$ & Control variable \\
\hline Pressure & Blower drive voltage & Duct dampers & Manifold pressure \\
\hline Speed & Motor voltage & Lamp load & Motor speed \\
\hline Voltage & Motor drive voltage & Lamp load & Generator voltage \\
\hline Flow & Pump drive voltage & Line valves & Flow rate \\
\hline Position & $\begin{array}{l}\text { Operator motor } \\
\text { voltage }\end{array}$ & none & Cart position \\
\hline Level & Pump speed & Auxiliary pump & Tank level \\
\hline Temperature & Hot water flow rate & Cold water flow rate & $\begin{array}{l}\text { Reservoir } \\
\text { temperature }\end{array}$ \\
\hline
\end{tabular}




\section{UNIT OPERATIONS STATIONS}

The unit operations stations are multiple-input, multiple-output systems. All of them are typified as "slow" systems.

Heat Exchange

Station \#8, the Heat Exchange station, uses the same equipment as the Temperature Control Station described above. The data available are reservoir temperature, inlet \& outlet temperatures for the cool water loop and the hot water loop. The flow rate of the hot water loop is continuously variable. The flow rate of the cool water loop can be set to one of 4 different values by using solenoid valves, all under web-user control.

\section{Dehumidification}

Station \#9, the Dehumidifier, is a conventional domestic, freon-cycle dehumidifier that has been instrumented for experimentation. The air inlets and outlets are monitored for temperature and humidity and the outlet air velocity is measured. The freon cycle temperatures are monitored. The power inlet to the compressor is monitored.

\section{Batch Dryer}

Station \#10, the Batch Dryer, is an electric-heated dryer that has 8 trays of sand distributed throughout the dryer. The trays are weighed by individual load cells. An experiment is run remotely by having water added to the sand trays, turning on the dryer and observing temperature $\&$ weights as a function of time. The load cells are connected to an eight-channel amplifier that sends the voltage signals to the data-acquisition computer.

\section{Gas-fired Heater}

Station \#11, the Gas-Fired Heater, is a conventional gas-fired domestic water heater. The inlet and outlet temperatures and the flow rate of the flowing water are monitored; the flow rate of the natural gas is monitored. The inlet temperature of the combustion air and the flue gas temperatures are monitored. The flue gas composition is monitored $\left(\mathrm{CO}_{2}, \mathrm{CO}\right.$ and $\left.\mathrm{O}_{2}\right)$. The water flow rate and the combustion air flow resistance can be varied by Web-user control.

Packed-bed Absorption Column

Station \#12, the packed-Bed Absorber, is a 3-inch diameter by 6-foot tall glass column packed with glass hollow cylinders. The data acquisition software monitors the inlet flow rates of the gas (air) and liquid (water) and the pressure drop across the column. With this capability, only hydraulic characteristics of the column can be determined. We are going to add the capability of putting a strippable component in the water and monitoring the concentration of that component in the effluent water and the air streams.

Flow through Porous Media

Station \#13, flow through porous media, is realized in a set of pipes packed with glass beads. They are of 2 different diameters and 2 different lengths. The flow rate into the porous media is controlled by a variable speed lab pump. The inlet pressure is monitored with a pressure transducer. 
Heat Exchange -- 2

Station \#14, another Heat Exchange station, is a standard shell-and-tube heat exchanger. The data available are inlet $\&$ outlet temperatures for the cool water loop and the hot water loop. The flow rate of the hot water loop is continuously variable. The flow rate of the cool water loop can be set to one of 4 different values by using solenoid valves, all under web-user control.

\section{Software}

The systems are operated by client programs using LabVIEW software on desktop computers at each control station. The software operates the equipment under the conditions of parameters as chosen by the (Web-User) operators.

\section{Web Environment}

All stations are available for experimentation via the World Wide Web. Experiments run via the Web can be run in the "batch" mode or live interactively with a newly developed Java applet or Visual Basic interface. The connection paths for running a batch-mode experiment are diagrammed in Figure 3.

In the lab at UTC, a computer is acting as a Web server and a "lab" server. Using the Microsoft Internet Server, it communicates with the Web user as a standard Web server by receiving requests for pages and returning them to the Web user.

When a request for an experiment is sent by a Web user, it goes to a different, custom-written (LabVIEW) server. This server is at port 8080 on that same machine, rather than the standard

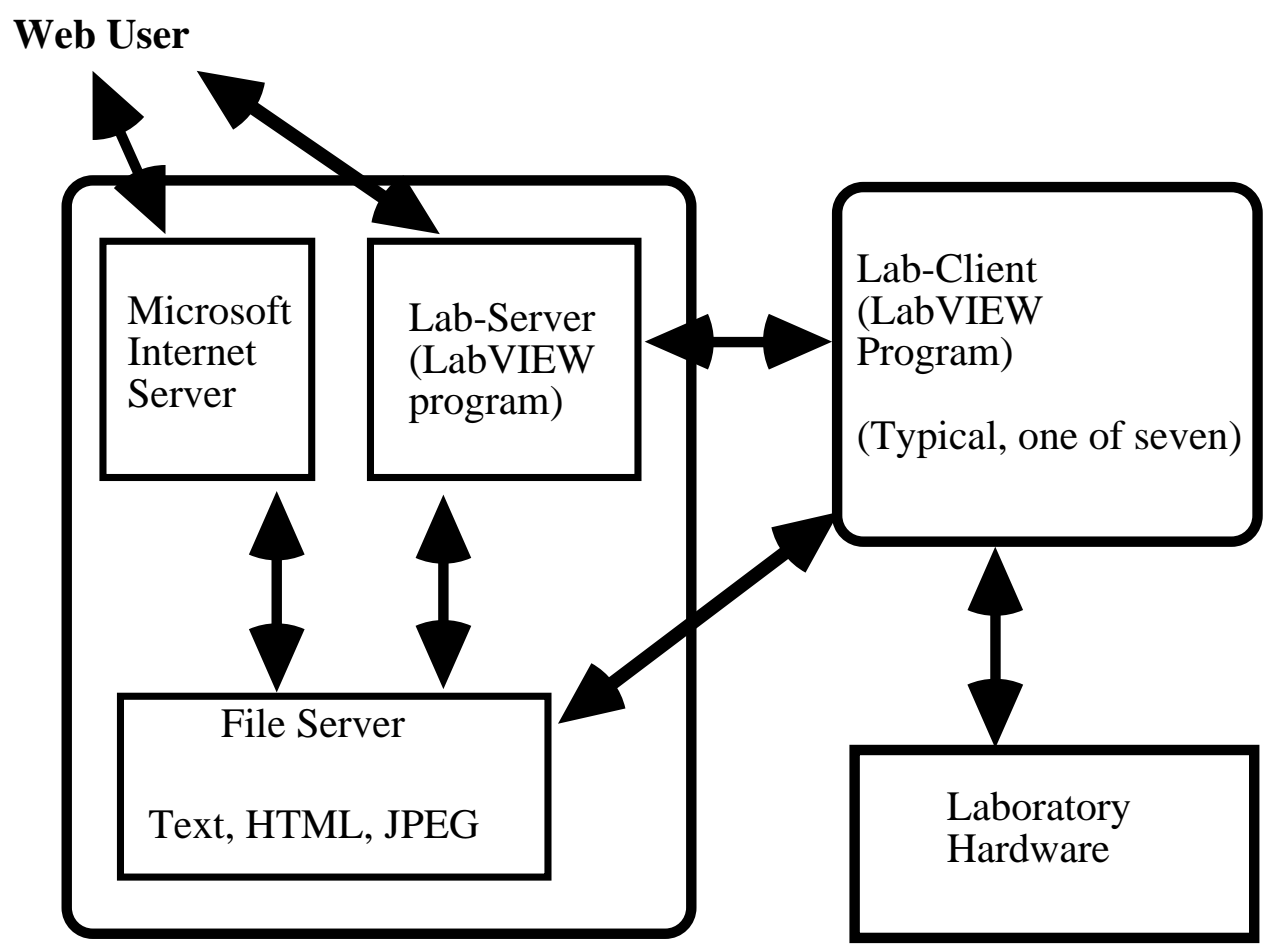

Figure 3. Connection diagram of laboratory units 
Web port of 80. The Lab-Server receives the information necessary to complete an experiment and parses that information. This server then returns a first response page to the Web user. This first response page tells the Web user that the experiment has been started or has been queued, if the equipment is busy.

Then the Lab-Server builds and saves to the file server several HTML pages that will contain the output from the experiment when the experiment is completed. It also writes on the file server a file that contains the information necessary for the lab station computer (Lab-Client) to run an experiment. This file is given the name of the targeted Lab-Client.

The Lab-Client machine, when seeing an appropriately named file show up on the file server, reads the file and conducts the experiment that is defined therein. It also deletes the file,

indicating to the Lab-Server that another experiment can be queued up. The Lab-Clients take action that differs depending on whether they are "fast" or "slow" systems.

\section{"Fast" Stations}

The "fast" station are most amenable for running experiments in the batch mode. With the slower speeds some people experience on the Internet, a 10-second experiment can be completed while the first response page is being transmitted. The Lab-Client collects the data for an experiment and writes the complete data file when the experiment has completed. This is the fastest way for these experiments to be conducted.

The Lab-Server waits for the data file to be written (the Lab-Server told the Lab-Client what the name of the data file was to be and where it was to be stored). When the Lab-Server sees the results file, it reads the file, constructs the appropriate results graphs and saves the graph images as jpeg files on the file server. The Web user's browser will automatically call for the results pages to be downloaded at the appropriate time (client pull).

\section{"Slow" Stations}

The "slow" station are not so amenable for running experiments in the batch mode. Some of these experiments can last for tens of minutes, if not longer. For these systems, the Lab-Client collects the data for an experiment and writes the data to a data file while the experiment is being conducted.

The Lab-Server again waits for the data file to begin to be written (the Lab-Server again told the Lab-Client what the name of the data file was to be and where it was to be stored). When the Lab-Server sees the results file, it reads the file, constructs the appropriate results graphs and saves the graph images as jpeg files on the file server. The Lab-Server continues to periodically read the data file, construct updated graphs and post jpeg files while the experiment continues and until it completes. The Web user's browser will automatically call for the results pages to be downloaded at the appropriate time. To the Web user, it appears that the graphs are being updated in real time. There is, of course, the normal Web-delay, so it is not actually "real" time. 


\section{Real Time Experiments}

For the "slow" systems, two developments have been made to allow very close to "real" time operation of the equipment via the Web. One is a Java applet that runs on most current web browsers. The other is a Visual Basic program that runs on Windows 95 and NT stations. With these application, there is as little as 1 second's delay between an operating command being issued at a Web user's computer and the execution of the command by the Lab-Client. These applications allows the user to send control commands to the laboratory and observe (in real time) the response of the system. These are both available on the Web site for downloading.

In the event of more than one user trying this, the Lab-Client obeys the commands of the first-tocome user and allows subsequent users to observe only. When the controlling user quits, another user becomes the "controlling" user.

\section{Experiments}

Seven different experiments can be run on each of the seven controls laboratory stations, as listed in Table 3. The desired web experiment is chosen by a graphic web page shown in Figure 4.

The software runs an experiment, collects data and writes the data on a computer hard disk at the end of each experiment. The Lab-Server computer draws a time-response graph of the data and posts the graph on the Web. Both the results data file and the graph are available to the Web user.

\section{System Dynamics or System Identification}

Students conduct experiments on the system of their choice. The block diagram for the singleinput, single output system is shown in Figure 5. The "Lab-Client" in the diagram is the PC with the LabVIEW client software. The experimental parameters are supplied by the Lab-Server from specifications of the Web user. 
Table 3. Controls Laboratory Experiments available.

System identification (1-5) and controller design (6 \& 7)

\begin{tabular}{|c|c|c|}
\hline & Name & Application \\
\hline 1 & Constant input & $\begin{array}{l}\text { Developing the steady-state operating curve for the } \\
\text { system }\end{array}$ \\
\hline 2 & Step input & $\begin{array}{l}\text { Finding the first-order plus dead-time (FOPDT) } \\
\text { parameters }\end{array}$ \\
\hline 3 & Sine input & Developing the Bode plot \\
\hline 4 & Pulse input & Refining the FOPDT parameters \\
\hline 5 & Custom input & $\begin{array}{l}\text { Design your own input function. Ramp, sawtooth, } \\
\text { triangle, for examples. }\end{array}$ \\
\hline 6 & $\begin{array}{l}\text { Proportional } \\
\text { feedback }\end{array}$ & $\begin{array}{l}\text { Verifying controller design. Determining region of } \\
\text { stability, quarter decay, offset, etc. }\end{array}$ \\
\hline 7 & $\begin{array}{l}\text { Proportional-integral } \\
\text { feedback }\end{array}$ & $\begin{array}{l}\text { Verifying controller design. Determining region of } \\
\text { stability, quarter decay, offset, etc. }\end{array}$ \\
\hline
\end{tabular}

The "constant input" experiment is the simplest. The control station (Lab-Client) supplies a constant value input signal to the hardware equipment and collects the data for the time specified by the user. In the case of pressure, flow, voltage, speed and level stations, where the Web user may specify different load-parameters, the computer sends signals to take the load-changing action. The desired experimental parameters are specified on a forms web page, such as shown in Figure 6.

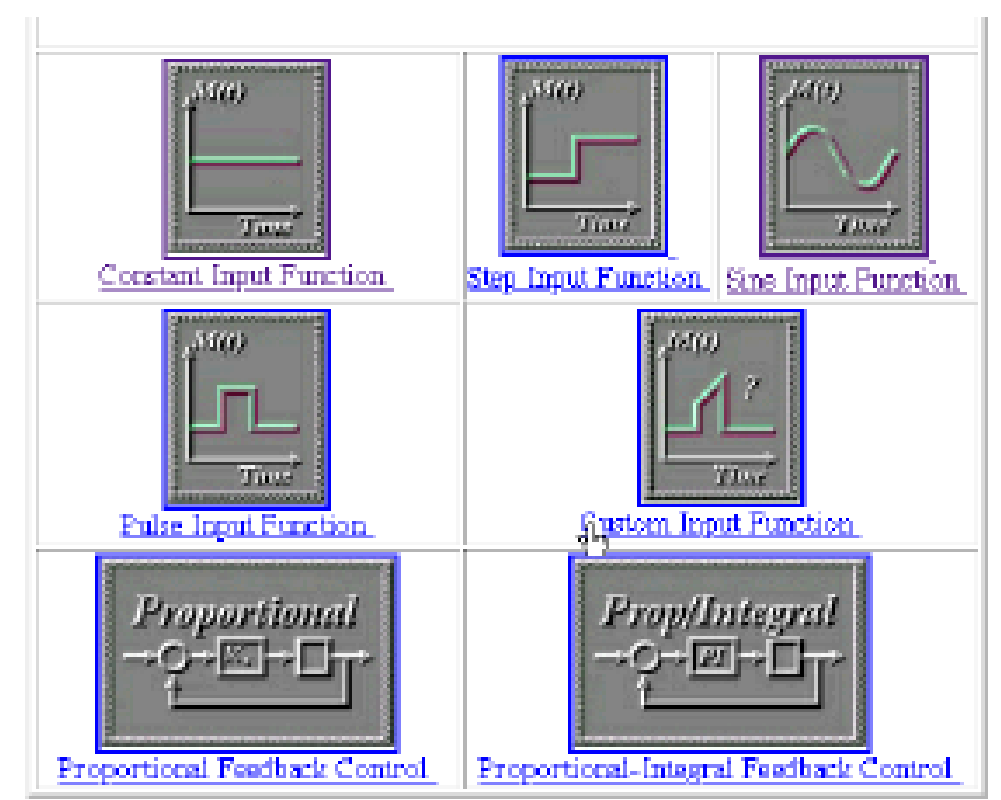

Figure 4. Selection page for Experiment type
Figure 7 shows the results of an experiment on the pressure control system for a constant input signal of 50\%, one of the exhaust ducts closed and an experiment lasting 10 seconds. The pressure (on the y-axis) is plotted versus time (on the $\mathrm{x}$ axis). In the first few seconds, the blower is starting up from an "off" condition. Notice the signal at "steady-state" (from about 3 to 10 seconds) has noise, also. We ask our students to quantify that. 


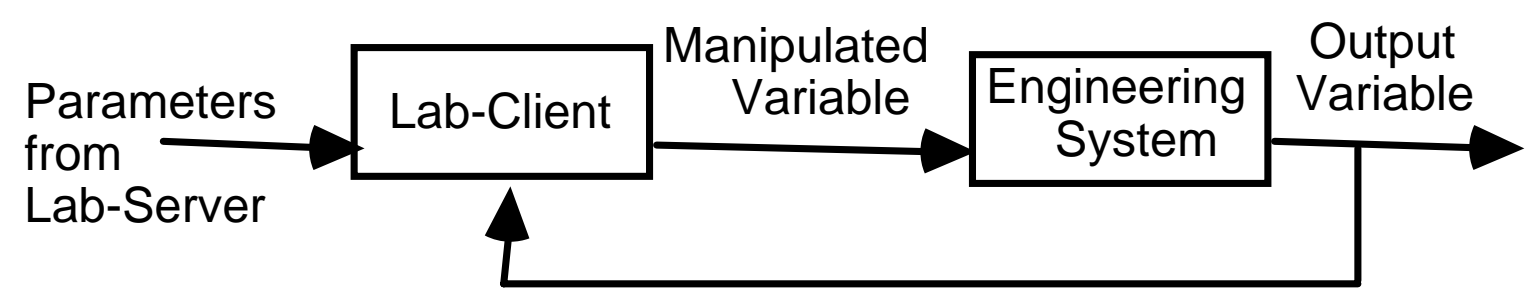

Figure 5. Block diagram for system dynamics experiments

\section{To run a Step Input Experiment for the Pressure System ENTER THE DATA BELOW}

\begin{tabular}{|c|c|c|}
\hline \multicolumn{3}{|c|}{ Uas Imormation } \\
\hline Enter your rome & Enter your location & Enter your e-msil ad dress \\
\hline Jin Heary & Chattornoge. & jin-hearsouto ofu \\
\hline \multicolumn{3}{|c|}{ Experimastel Informetios for "Swp lnput Furction" Experiment } \\
\hline $\begin{array}{l}\text { System } \\
\text { Presaure }\end{array}$ & $\begin{array}{l}\text { Lenth of enperiment (soc) } \\
\text { If } \\
\text { Leh Wasud }\end{array}$ & 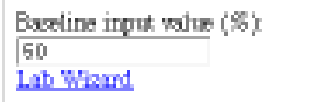 \\
\hline $\begin{array}{l}\text { Beight of the Step (\%) } \\
\text { 40 } \\
\text { Lab wiand }\end{array}$ & \multicolumn{2}{|c|}{$\begin{array}{l}\text { Time at vhich Step cecurs (aec): } \\
5 \\
\text { Leh wased }\end{array}$} \\
\hline \multicolumn{3}{|c|}{ Configuration Informstion for Prequre System } \\
\hline Doumpers $\# 1 \& \& 2$ & $\begin{array}{l}f 1-\operatorname{closed}(\operatorname{kec}): 12 \\
f 1-\operatorname{cpen}(\overline{k e c}): 12\end{array}$ & $\begin{array}{l}2 z \text { - cloced (sec) } \sqrt{6} \\
x Z \text { - open }(\sec ) \sqrt{6}\end{array}$ \\
\hline PUA EXPERIMERT & CLEAR PAPAMEIREO & Equipment Pictures \\
\hline
\end{tabular}

Figure 6. Specification form for the experiment

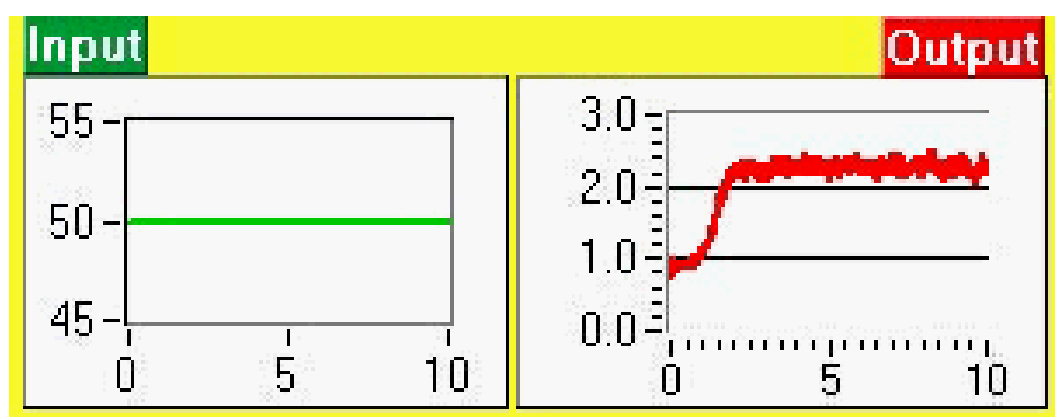

Figure 7. Response of constant input of $50 \%$ for the pressure system

The position (on the $y$-axis) is plotted versus time (on the $\mathrm{x}$-axis).
From a series of steadystate experiments, the user can construct a steadystate operating curve for the system. There are 1,951 data points in the graph of Figure 7, indicating a sampling frequency of the data acquisition system of about $195 \mathrm{~Hz}$.

The "step input" experiment provides a step change in the input signal. The control station (LabClient) initially supplies a constant value input signal to the hardware equipment and then instantaneously changes the input by an amount and at the time specified by the user. As mentioned above, different load-parameters are handled by the computer. Figure 8 shows a portion of the results of an experiment on the position control system for an initial input signal of $50 \%$, a step increase of $40 \%$ at 5 seconds and an experiment lasting 10 seconds.

From this type of experiment, students are asked to find the empirical first-order-plus-dead-time parameters for the system. There are 215 data points in the graph of Figure 8, indicating a sampling frequency of the data acquisition system of about $72 \mathrm{~Hz}$. The computer at this position station is slower than the one on the pressure station. 


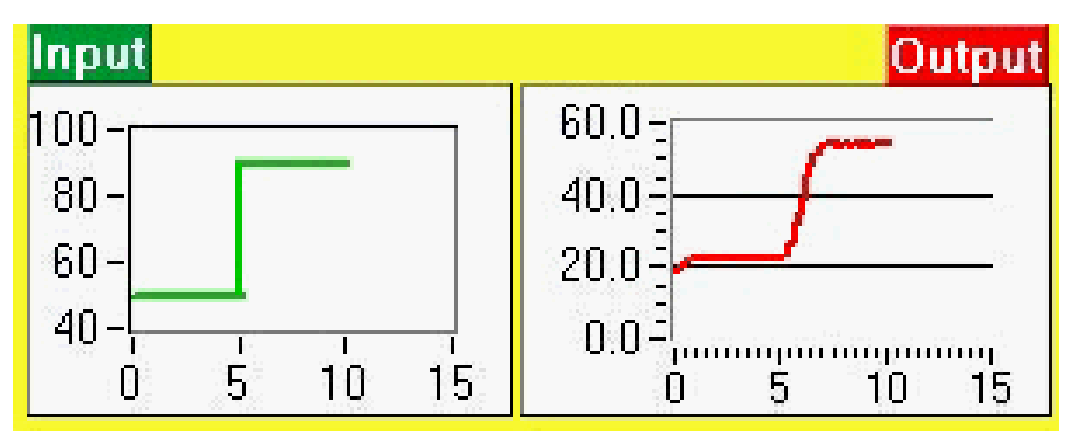

Figure 8. Response of step input from $50 \%$ to $90 \%$ for the position system
The "sine input"

experiment provides a sinusoidal variation in the input signal. As mentioned above, different load-parameters are handled by the computer. Figure 9 shows the results of an experiment on the flow control system for a sinusoid input function with amplitude of $30 \%$, centered about $60 \%$,

a frequency of $0.2 \mathrm{~Hz}$ and an experiment lasting 10 seconds. The flow rate (on the y-axis) is plotted versus time (on the $\mathrm{x}$-axis). From this type of experiment, students are asked to find the empirical amplitude ratio and phase shift for this frequency.

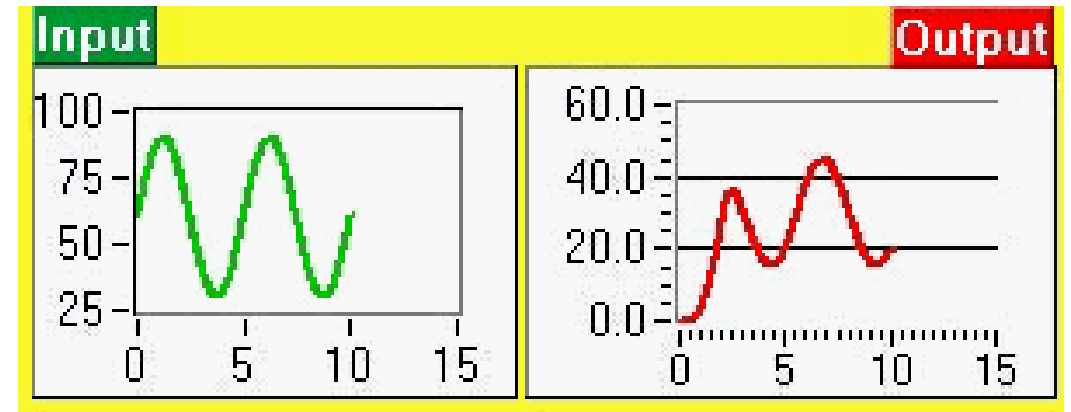

Figure 9. Response of sine input with amplitude of $30 \%$ centered at $60 \%$ for the flow system
There are 632 data points in the graph of Figure 9, indicating a sampling frequency of the data acquisition system of about $63 \mathrm{~Hz}$. This relative slowness is due to the fact that the computer at this flow station is doing some averaging of the flow readings. 


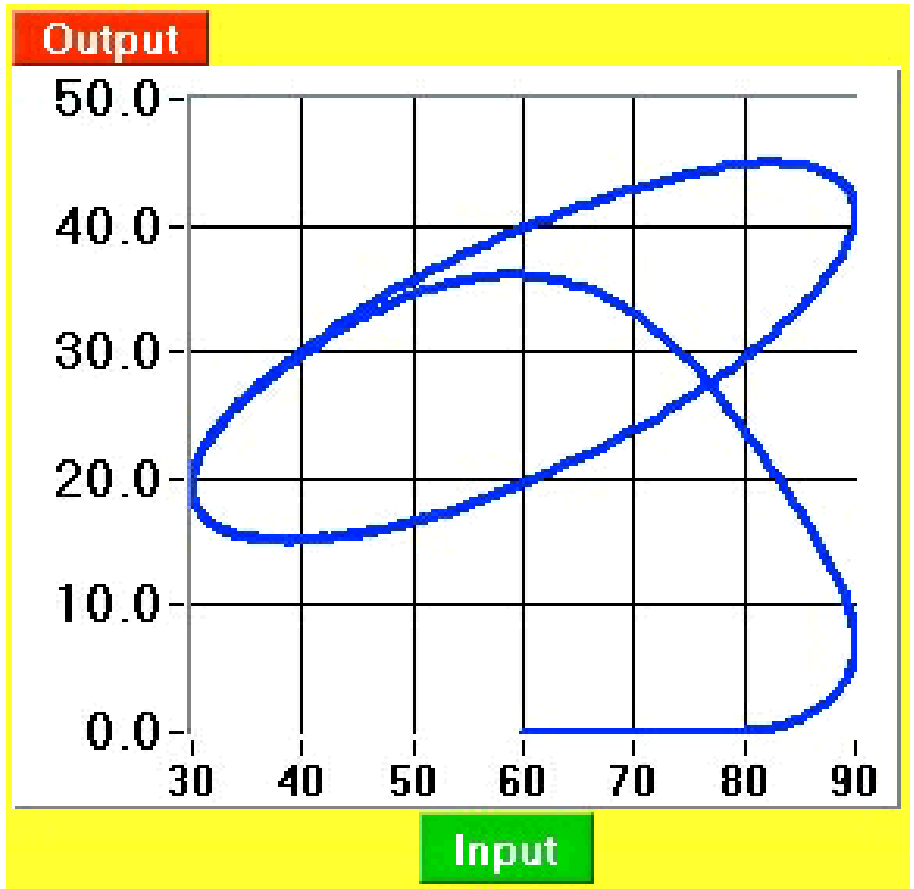

Figure 10. Lissajous response of sine input with amplitude of $30 \%$ centered at $60 \%$ for the flow system
These results can also be plotted as the output versus the input and produce a Lissajous plot. This is shown in Figure 10. The start-up transients are responsible for the spurious part of the curve in the lower right corner.

By conducting experiments at a number of different frequencies, the students can construct a Bode plot. We have our students do that. From the Bode plot they determine the empirical system order, the ultimate frequency and the ultimate controller gain. 
The "pulse input" experiment provides a step change in the input signal and then a return to the initial value of the input signal. The control station (Lab-Client) initially supplies a constant value input signal to the hardware equipment and then instantaneously changes the input by an amount and at the time specified by the user. As mentioned above, different load-parameters are handled by the computer.

Figure 11 shows the results of an experiment on the voltage control system for an initial input signal of $40 \%$, a step increase of $40 \%$ at 4 seconds followed by a step down (of $-40 \%$ ) at

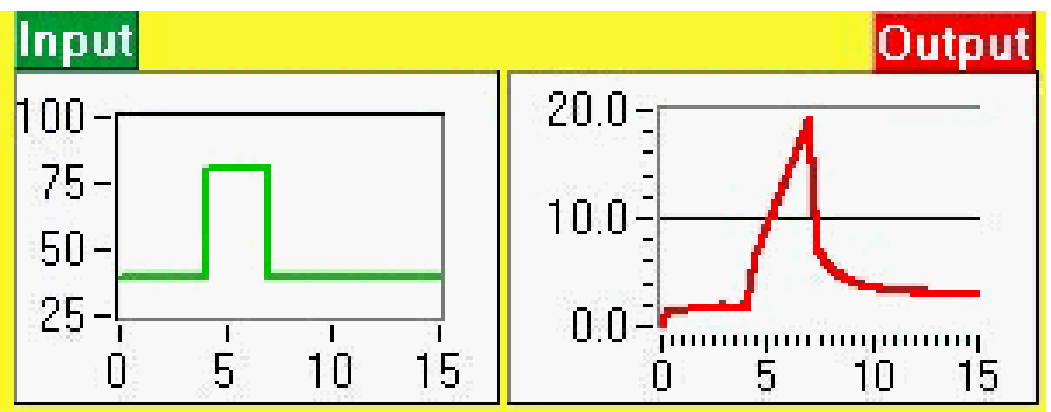

7 seconds and an experiment lasting 10 seconds. The voltage (on the $y$-axis) is plotted versus time (on the $\mathrm{x}$-axis). Notice that the self-excited DC-generator exhibits considerable hysteresis in this experiment.

Figure 11. Response of pulse input from $40 \%$ to $80 \%$ \& return to $40 \%$ for the voltage system

From this type of experiment, students can again find the empirical first-order-plus-dead-time parameters for the system. Additionally, with Fourier transform methods, the entire Bode plot can be constructed from this one experiment. This system has a sampling frequency of the data acquisition system of about $195 \mathrm{~Hz}$.

The "custom input" experiment provides a chance for the Web user to design any input waveform for an experiment. The waveform is entered as a table of time-input data pairs. The control station interpolates linearly between data points. The control station (Lab-Client) supplies an input signal to the hardware equipment that follows the time-input data table specified by the user. As mentioned above, different load-parameters are handled by the computer. Figure 12 shows the results of an experiment on the speed control system for an initial input signal that goes from $0 \%$ to $50 \%$ (linearly) over 4 seconds, stays at $50 \%$ for 3 seconds, then increases (linearly) to $100 \%$ over the next 3 seconds. If the experiment is longer than the waveform specification, the waveform is repeated with the period specified by the waveform data specification. This experiment lasted 20 seconds. The speed (on the y-axis) is plotted versus time (on the $\mathrm{x}$-axis).

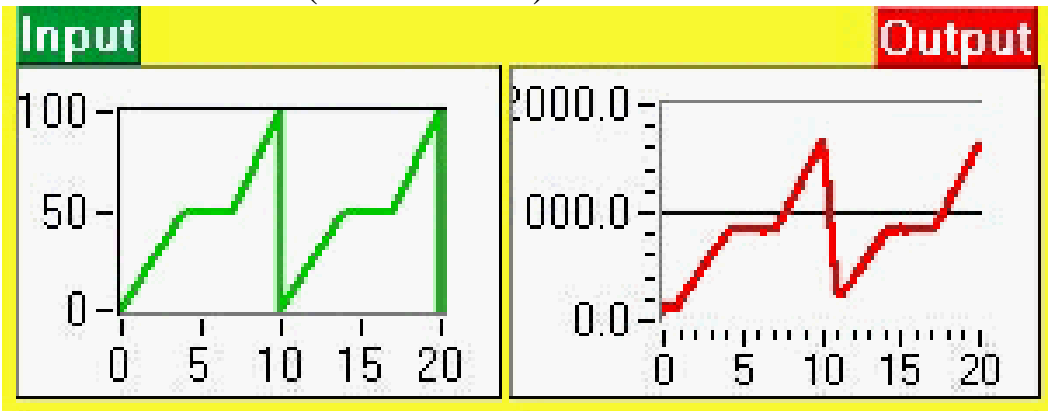

Figure 12. Response of custom input for the speed system
The most useful experiments that can be done with the custom specifications are ramp or a sawtooth waves. Notice in Figure 12, the speed system is able to keep up pretty well with the input signal changes except at the step change that occurs at a time of 10 seconds.

This system has a sampling frequency of the data acquisition system of about $195 \mathrm{~Hz}$. 


\section{Controller Design}

Students design one of two controllers. The block diagram for the feedback controller is shown in Figure 13. The "Controller" in the diagram is the PC with the LabVIEW client software. The "Desired Set Point" and other parameters are supplied by the Lab-Server from specifications of the Web user.

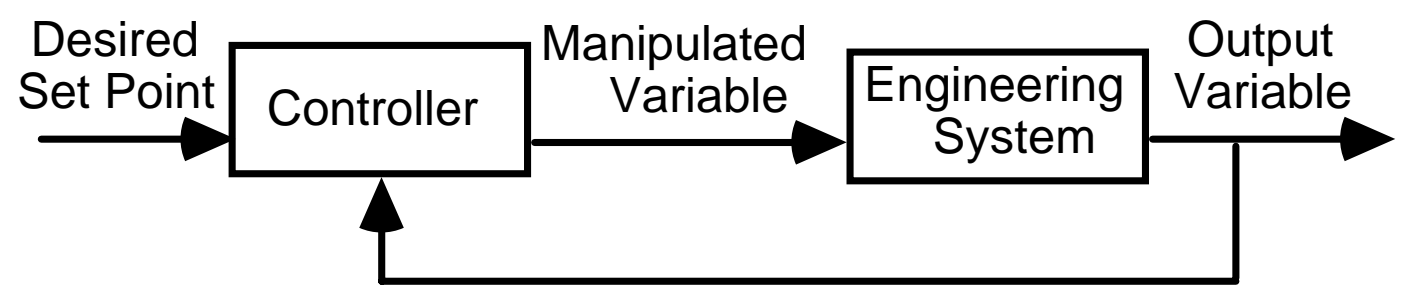

Figure 13. Block diagram for feedback systems

The "proportional feedback input" experiment provides a chance for the Web user to design a proportional feedback controller. The control station (Lab-Client) supplies an input signal to the hardware equipment that is equal to the "error" (the difference between the set-point and the output signal) multiplied by the controller gain. A "bias" as specified by the user is added to the input signal. As mentioned above, different load-parameters are handled by the computer.

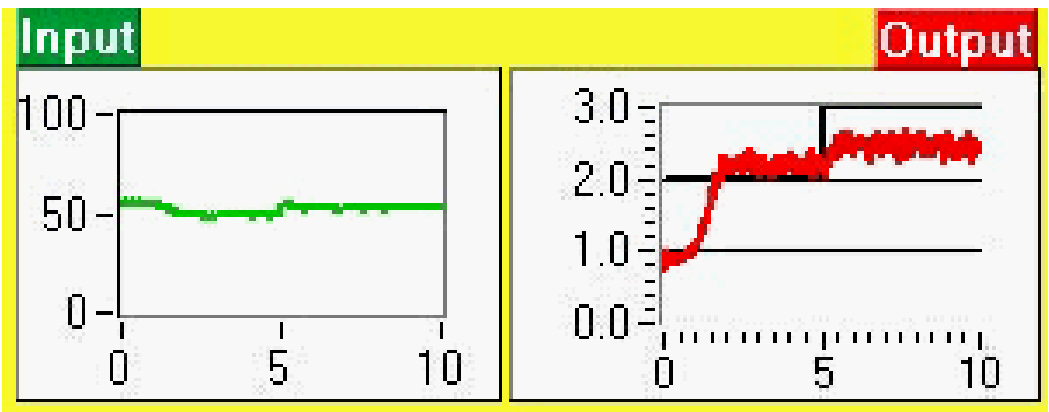

Figure 14. Response of proportional feedback control for the pressure system
Figure 14 shows the results of an experiment on the pressure control system for a set point of $2 \mathrm{~cm}-$ $\mathrm{H} 2 \mathrm{O}$ that changes to $3 \mathrm{~cm}-$ $\mathrm{H} 2 \mathrm{O}$ at 5 seconds. The controller gain is $5 \% / \mathrm{cm}-$ $\mathrm{H} 2 \mathrm{O}$. The pressure (on the $\mathrm{y}$-axis) is plotted versus time (on the $\mathrm{x}$-axis).

Notice the offset of about $0.5 \mathrm{~cm}-\mathrm{H} 2 \mathrm{O}$ in this experiment. This offset is one of the characteristics of a proportional control system.

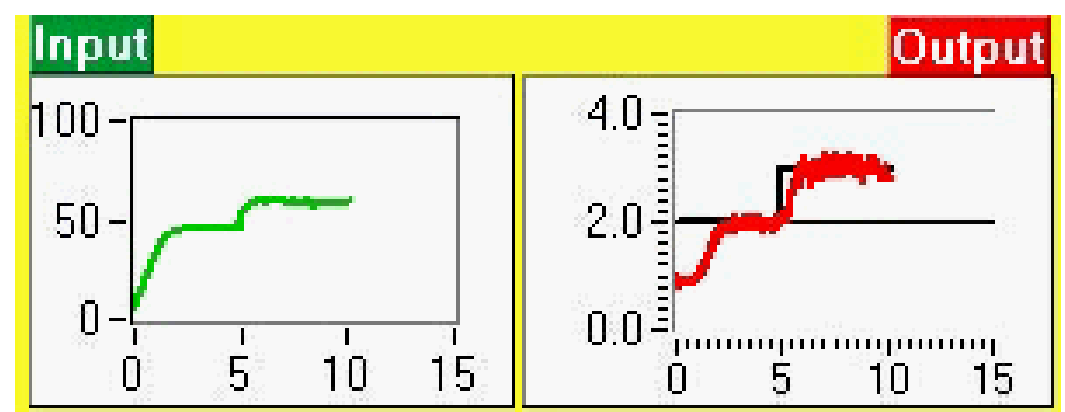

Figure 15. Response of proportional-integral feedback control for the pressure system
The "proportional-integral feedback input" experiment provides a chance for the Web user to design a proportionalintegral feedback controller. The control station (Lab-Client) supplies an input signal to the hardware equipment that is equal to the "error" plus the integral of the 
error (divided by the integral time constant) multiplied by the controller gain. As mentioned above, different load-parameters are handled by the computer. Figure 15 shows the results of an experiment on the pressure control system for a set point of $2 \mathrm{~cm}-\mathrm{H} 2 \mathrm{O}$ that changes to $3 \mathrm{~cm}-\mathrm{H} 2 \mathrm{O}$ at 5 seconds. The controller gain is $5 \% / \mathrm{cm}-\mathrm{H} 2 \mathrm{O}$ and the integral time constant is 0.2 seconds. The pressure (on the $\mathrm{y}$-axis) is plotted versus time (on the $\mathrm{x}$-axis).

The fluctuations in the Pressure output graph in the range from 7 to 10 seconds are due to measurement noise. There is direct measurement noise and also noise amplified by the controller due to the measurement noise.

\section{Modeling}

The lab course involves modeling of the system which corresponds to the experimental station being studied. We have the students use first-order-plus-dead-time models of the physical systems with Excel. They model the step response, the sine response, the Bode plot, the root locus plots and the responses to step changes in set points for feedback controllers.

These Excel models are available on the Web site. The students use their experimentally determined parameters to apply the models.

\section{Course Management}

Beginning in the Spring, 1996, semester, we have offered a "Web"-based class. The equipment was available via the Web for 24 hours a day, 7 days a week. This class is managed mostly without "face-to-face" meetings. Laboratory information and assignments are provided on the Web server. The experiments, the analysis of the data, the controller design and the reporting were done at times chosen by the students. Discussion among students is available via a listserv. Students' reports are submitted via e-mail. As the student assignments are received, they are posted on the Web for other students to review.

The stations are pre-emptied when a "local, hands-on" student is using the equipment. This is usually less than 20 hours in a semester. Other than that, all comers are treated equally. Each station could be reserved by implementing a password for users; this has not been necessary yet.

This year (1997-1998) 6 students have chosen this method of completing the laboratory; the regular hands-on students number about 30. The students who choose the Web-Lab version of the course are typically part-time students with (usually) full time jobs and family responsibilities.

Observation of the performance of the students over the current school year leads to these qualitative observations: The Web-Lab students appear to understand the principles of the experiments as well as the hands-on students. The Web-Lab students seem to perform as well in the corequisite lecture course as hands-on students. The Web-Lab students appear to be able to design controllers with as much ability as the hands-on students. Further assessments of the relative performance of the web-using students is going to be done.

\section{Faculty Workload Equivalent}

The amount of work that went into putting this (existing) laboratory on the web was about half the amount of work of developing the lab originally from scratch. The previously prepared lab 
manual had to be significantly revised for applicability to the Web user. The Web site took significant preparation time. The proof of the concept took about two months. After that, each additional station took another month. The time consumption was largely due to the newness of the medium for the developer.

\section{Strengths and Challenges}

Sharing resources is one strong point of this ability to teach system dynamics and controls laboratory via the internet. The investment in equipment at UTC can be shared by other engineering schools. Previously, we have actively used the equipment for about 6 hours a week for about 20 weeks per year. This is a very small utilization fraction (about 0.014) of the available hours in a year. Providing learning opportunities for students with scheduling conflicts is another strong point of this ability to teach engineering laboratory via the Web.

When first installed, the main weaknesses were equipment or communication bugs. Nearly all of these have been worked out. With NSF support, all stations in the controls lab have been upgraded. They now have Windows NT 4.0 operating system with Pentium Pro Intel processors. All computers (and not engineering equipment) are on uninterruptible power supplies, so even across brief power outages, the lab remains up and available.

The main challenges being experienced now are the common challenges of distance education. These challenges include student motivation and record keeping.

The fact that the Web-Lab students do not have hands-on experience with senses is considered a drawback. The experiments can be heard by users that can use RealAudio (a free plug-in to browsers, linked on the Web-Lab site). Visual and tactile sensing of experimental operation is, of course, not available. This is, however, identical to an industrial situation where the operator or engineer may remotely be operating equipment. Also, equipment problems and repairs are all handled seemingly by magic, to the web-user.

\section{Future}

UTC is committed to continuing to develop and expand this Web-available laboratory. Extending the experiments to include unit operations labs is under development.

We are interested in sharing the software with any other university that wishes to bring its labs on-line. We envision a World Wide Web-Lab in which students and researchers can run experiments on equipment that would not otherwise be available or be utilized.

\section{Acknowledgments}

UTC's Center of Excellence for Computer Applications and the National Science Foundation through DUE-ILI Grant 97-51024 have supported this effort with generous grants. Other support has been received from the UTC College of Engineering and Computer Science, National Instruments, Rosemount Controls, Plant Engineering Consultants and Analog Devices. 


\section{References}

1. Henry, Jim, (1993), "Engineering Controls Systems with LabVIEW," Scientific and Engineering Applications for Macintosh, Woburn, MA, August, 1993. Abstract available via Web at http://chem.engr.utc.edu/Henry-Pub

2. Henry, Jim, (1995), "LabVIEW Applications in Teaching Controls Systems Laboratories," ASEE Annual Meeting, Anaheim, CA, June, 1995. Abstract available via Web at http://chem.engr.utc.edu/Henry-Pub

3. Henry, Jim, (1996) "Details of Web-based Controls Laboratory Hardware and Software," available via Web at http://chem.engr.utc.edu/Henry-Pub

\section{Biographical Information}

\section{JIM HENRY}

Jim Henry is Professor of Chemical and Environmental Engineering at the University of Tennessee at Chattanooga. He has also taught at Tulane University, Prairie View A\&M University and the University of Jordan in Amman.

Dr. Henry received his Ph.D. from Princeton University. His B.S.Ch.E. was received from Rice University. He completed a postdoctoral year at Yale University.

Dr. Henry has also worked for a U.S. Department of Energy research lab, DuPont Company and Chevron Oil.

For the past 8 years, he has focused on developing data acquisition and control application in laboratories for controls systems, chemical and environmental engineering. He also teaches the courses in principles and in design of chemical and environmental engineering processes. His research is in the area of applied control systems, fuzzy control and distillation control. 